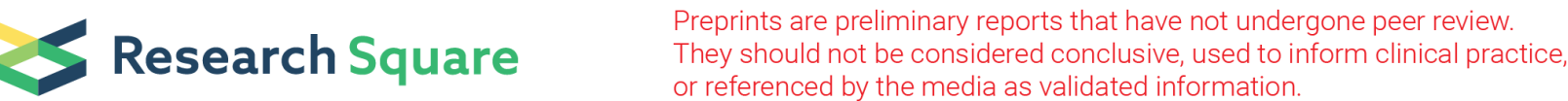

\section{Effect of Huangqin Decoction on Regulating Intestinal Flora in Colitis Mice Characterized as The Inhibition of NOD2-Dependent Pathway}

\section{Shaowei Huang}

Guangzhou University of Chinese Medicine

Jinrong He

Guangzhou University of Chinese Medicine

\section{Yanping Chen}

Guangzhou University of Chinese Medicine

\section{Xiaojing Wang}

Guangzhou University of Chinese Medicine

\section{Yanyang Li}

Guangzhou University of Chinese Medicine

\section{Yulin Su}

Guangzhou University of Chinese Medicine

\section{Ruyan Wen}

Guangxi University of Chinese Medicine

\section{Xiuling Li}

Sun Yat-sen University

\section{Guanghua Yang}

Guangzhou University of Chinese Medicine

\section{Shuang Luo}

Guangzhou University of Chinese Medicine

Lian Zhou ( $\sim$ zl@gzucm.edu.cn)

Guangzhou University of Chinese Medicine https://orcid.org/0000-0001-5740-9083

\section{Xia Luo}

Guangzhou University of Chinese Medicine Affiliated Hospital of Traditional Chinese Medicine: Hainan Province Hospital of Traditional Chinese Medicine

\section{Research}

Keywords: Huangqin decoction, Colitis mice, NOD2-dependent pathway, intestinal flora

Posted Date: December 30th, 2020 
DOl: https://doi.org/10.21203/rs.3.rs-136209/v1

License: (c) (1) This work is licensed under a Creative Commons Attribution 4.0 International License. Read Full License

Version of Record: A version of this preprint was published at Pharmaceutical Biology on December 30th, 2021. See the published version at https://doi.org/10.1080/13880209.2021.2017981. 


\section{Abstract}

Background: Dysfunction of the intestinal flora is an important factor in the occurrence and development of ulcerative colitis (UC). Chinese herb Huangqin decoction (HQD) can regulate intestinal flora in UC mice, yet its specific mechanism remains unclear. Our study aimed to clarify the mechanism of HQD in regulating intestinal flora of UC mice.

Methods: 3\%DSS - induced colitis mice were used to explore the pharmacodynamics of HQD. Colonic bacterial infiltration and the changes of intestinal flora were detected by FISH and 16SrDNA. Expression of Reg $\varangle$ y and PRRs (NOD2, TLR5, TLR4) were detected by FCM and WB, respectively. In addition, WB, SqPCR, or IHC were used for the expression of Nod2, MyD88, Rip2, and NF-kB p65 in colon. Cytokines were determined by ELISA.

Results: HQD significantly restored the weight, the colonic length, and peripheral blood cell counts of colitis mice; reduced the DAI score and the histological score. 16SrDNA identification showed HQD regulated the balance of intestinal flora. Moreover, the expression of Reg $₫ y$ was suppressed and colonic bacterial infiltration was prevented by HQD. Furthermore, the results of WB showed expression of NOD2 and TLR4 was inhibited by HQD, especially NOD2. And the data of WB, SqPCR and IHC explained that the NOD2-dependent pathway was inhibited by HQD.

Conclusions: Our results reveal the mechanism of $\operatorname{HQD}(1 \mathrm{~g} / \mathrm{kg})$ in regulating the intestinal flora of colitis mice, which may be closely characterized as the inhibition of the activation of Pattern Recognition Receptors (PRRs), especially NOD2.

\section{Background}

Ulcerative colitis (UC), a chronic inflammatory bowel disease(IBD) with recurrent episodes, is difficult to cure because of its complicated etiology ${ }^{[1]}$. Accumulating researches had shown that the occurrence and development of UC was closely related to the disorder of intestinal flora ${ }^{[2,3]}$. A large number of intestinal symbiotic bacteria will form a microbial barrier in the physiological state, which can resist the invasion of pathogenic bacteria ${ }^{[4]}$. However, the microbial barrier was damaged due to the imbalance of intestinal flora, and then the bacteria invaded the intestinal epithelial cells, causing inflammation and even apoptosis of the intestinal epithelial cells, and destroying the normal physiological function of the intestinal tract. What's more, the abundance of probiotics such as Bifidobacterium and Lactobacillus in UC decreased significantly, while the pathogenic bacteria such as Escherichia coli increased significantly ${ }^{[5]}$. Therefore, regulating the balance of intestinal flora plays an important role in the treatment of UC.

It has been reported that intestinal bacteria and pathogen-associated molecular patterns (PAMPs) triggered excessive activation of the immune system, released pro-inflammatory cytokines and further destroyed the intestinal barrier ${ }^{[6,7]}$. PAMPs, including lipopolysaccharides (LPS), flagellin, muramyl dipeptide (MDP), etc., are recognized by corresponding pattern recognition receptors (PRRs), which 
activates PRRs (LPS combined with TLR4, flagellin combined with TLR5 and MDP combined with NOD2) and their downstream signaling pathways to release inflammatory cytokines, recruit phagocytic cells, and regulate dendritic cells. In a study of PRRs, the nucleotide-binding oligomerization domain-containing protein 2 (NOD2)-dependent pathway has been found to be important among multiple inflammatory signaling pathways, and Nod2 is the first susceptible gene that is found to be associated with IBD ${ }^{[8]}$. The number of bacteria adhering to the intestinal mucosa increased in UC patients with NOD2 gene mutation. In addition, some researches have also reported that the expression of Toll-like receptor (TLR) 4 and TLR5 increased in UC mice ${ }^{[9,10]}$.

Accumulating evidences showed that Huangqin decoction (HQD), a well-known traditional Chinese herbal prescription documented in the book Treatise on Febrile Diseases from the Han dynasty, prevents intestinal carbuncles as well as UC. Nowadays, the prescription has been widely used in the current clinical treatment of $U C^{[11,12]}$, and its mechanism is mainly related to the maintenance of intestinal epithelial cell homeostasis, protection of intestinal barrier ${ }^{[13]}$, inhibition of TLR4/MyD88 signal pathway ${ }^{[14]}$, suppression of immune response, regulation of intestinal flora and so on ${ }^{[15,16]}$. However, there has little reports about the effect of HQD on the relation of intestinal PRRs and intestinal flora in patients with colitis. Thus, our study used DSS-induced colitis mice as a model of UC to explore the regulation of HQD on intestinal flora, which may be related to PRRs, especially NOD2.

\section{Materials And Methods \\ 2.1. Drugs and reagents}

HQD consists of the following component herbs: Paeonia lactiflora Pall., Glycyrrhiza uralensis Fisch., Ziziphus jujuba Mill. (purchased from Kangmei Pharmaceutical Co., Ltd.), and Scutellaria baicalensis Georgi (purchased from Guangdong He Xiang Pharmaceutical Co., Ltd.). Paeoniflorin and baicalin were purchased from Guangzhou Whiga Technology Co., Ltd. (Guangzhou, China). Liquiritin ( $\geq 98 \%$ purity), glycyrrhizic acid ( $\geq 98 \%$ purity), and wogonoside ( $\geq 98 \%$ purity) were purchased from Chengdu Feipude Biological Technology Co., Ltd. The cytometric bead array (CBA) assay kit was purchased from BD Biosciences Pharmingen (San Jose, CA, USA). DSS was obtained from MP Biomedicals (Santa Ana, CA, USA). Sulfasalazine tablets were purchased from Shanxi Tongda Pharmaceutical Co., Ltd. (Shanxi, China). The TRIzol reagent, NF-kB p65 gene primers, and receptor-interacting protein-2 (RIP2) gene primers were purchased from Invitrogen (Carlsbad, CA, USA). SYBR® Premix Ex Taq ${ }^{\text {TM }}$ (Tli RNase H Plus), DNase/RNase-free deionized water, NOD2 gene primers, and glyceraldehyde 3-phosphate dehydrogenase (GAPDH) reference gene primers were obtained from Dalian Bioengineering Co., Ltd. (Dalian, China). AntiTLR4 antibody, anti-MyD88 antibody, anti-Rip2 antibody and anti-NF-KB p65 antibody were purchased from Cell Signaling Technology (Boston, MA, USA). An anti-NOD2 antibody was purchased from Abcam (Cambs, UK). Protein markers were purchased from Fermentas (Burlington, ON, Canada). The enhanced chemiluminescence (ECL) substrate was purchased from Beyotime Institute of Biotechnology (Shanghai, China). 


\subsection{Preparation of HQD}

According to the original proportion (9:6:6:6; g), we weighed and mixed S. baicalensis, P. lactiflora, $G$. uralensis, and $Z$. jujuba and prepared 10 batches of a conventional decoction. Each was mixed with eight times the amount of water, soaked for $30 \mathrm{~min}$, then subjected twice to the first fire to boil for $25 \mathrm{~min}$ and simmering for about $35 \mathrm{~min}$, and filtered. The two filtrates were combined and subjected to rotary evaporation to obtain a solution equivalent to $2 \mathrm{~g} / \mathrm{mL}$ crude drug. The solution was diluted with ultrapure water to $0.5 \mathrm{~g} / \mathrm{mL}$ and further diluted with an equal volume of methanol to a final concentration of $0.25 \mathrm{~g} / \mathrm{mL}$. A test sample was obtained after centrifugation for $1 \mathrm{~min}$ and filtration through a $0.22-\mu \mathrm{m}$ membrane.

To prepare reference substances, $5 \mathrm{mg}$ of baicalin, paeoniflorin, glycyrrhizin, and glycyrrhizic acid, was dissolved in $10 \mathrm{~mL}$ of methanol and filtered through a $0.45-\mu \mathrm{m}$ microporous membrane. Paeoniflorin was diluted to a final concentration of $40 \mu \mathrm{g} / \mathrm{mL}$ with $50 \%$ methanol, and the other reference substances were diluted to $20 \mu \mathrm{g} / \mathrm{mL}$. All compounds were prepared as a single standard and mixed standard, followed by centrifugation for $1 \mathrm{~min}$ and filtration through a $0.22-\mu \mathrm{m}$ membrane.

The prepared HQD and reference substance solutions were analyzed by high-performance liquid chromatography (HPLC). The results of an HPLC chromatogram were imported into software (Chinese medicine chromatographic fingerprint similarity evaluation system 2004A) to analyze its fingerprint in an AIA (Analytical Instrument Association) format. The fingerprint of HQD sample S1 was used as a reference spectrum, and control maps were generated using average data. Fingerprint matching was performed by a multi-point calibration method to generate a control map. The following chromatographic conditions were used: a Kromasil C18 column $(250 \mathrm{~mm} \times 4.6 \mathrm{~mm}, 5 \mathrm{~m})$; column temperature: $30^{\circ} \mathrm{C}$; mobile phase $A$ : acetonitrile; mobile phase $B$ : water containing $0.1 \%$ phosphoric acid; linear elution gradient: 0-10 min, $10 \% \mathrm{~A}-11 \% \mathrm{~A} ; 10-35 \mathrm{~min}, 11 \% \mathrm{~A}-65 \% \mathrm{~A}$; flow rate: $1.0 \mathrm{~mL} \cdot \mathrm{min}^{-1}$; scanning wavelengths: $220-500 \mathrm{~nm}$; sample size: $10 \mu \mathrm{L}$.

\subsection{Animals}

C57BL/6 mice (male, 6-8-week-old, weight 18-22 g) were obtained from the Laboratory Animal Center of Guangzhou University of Chinese Medicine (Guangzhou, China) and acclimated for at least 3 days before experiments. The mice were housed in groups under specific pathogen-free conditions at a temperature of $24 \pm 1{ }^{\circ} \mathrm{C}$, humidity of $40-80 \%$, and a 12-h light/12-h dark cycle. All experiments were executed according to the guidelines approved by the Ethics Committee of Guangzhou University of Chinese Medicine.

\subsection{Induction of colitis and treatments}

The C57BL/ 6 mice were randomly divided into six groups ( $\mathrm{n}=12$ per group): control, model (DSS), sulfasalazine (500 mg/kg), low dose of HQD $(250 \mathrm{mg} / \mathrm{kg})$, medium dose of HQD $(500 \mathrm{mg} / \mathrm{kg})$, and high dose of HQD $(1,000 \mathrm{mg} / \mathrm{kg})$ groups. The mice in the control group had free access to sterile water, while those in the other groups drank 3\% DSS freely for 5 days and then drank sterile water. Meanwhile, the 
mice in the control and model groups were administered with sterile water, while the other four groups were given the corresponding medicines. The drugs were administered for a total of 10 days according to the mouse weight $(0.2 \mathrm{~mL} / 10 \mathrm{~g})$, and the experiment was carried out on day 11 . The grouping and treatment with HQD of the DSS-induced colitis mice are shown in Fig. 1.

\subsection{Assessment of colitis severity}

The disease activity index (DAl) score of colitis was determined as Cooper previously described ${ }^{[17]}$. For the assessment of the severity of colitis in mice, eating, water drinking, the hair color, feces, blood in the stool, and the body weight were carefully observed and recorded daily.

At the end of administration, peripheral blood was collected from eyes after anesthesia, then $20 \mu \mathrm{L}$ was fully mixed in an EDTA-2K anticoagulant tube, and used to count blood cells with an automatic blood cell analyzer. In addition, we cut colonic segments from the sacrificed mice and measured and recorded their natural length without stretching. The distal colon of $2.0 \mathrm{~cm}$ was fixed with $4 \%$ paraformaldehyde, dehydrated, and embedded in paraffin. The tissue was cut into about $4 \mu \mathrm{m}$ slices and stained with hematoxylin and eosin (HE). Then, the stained tissue was observed under an optical microscope, and a histological score was determined according to the standard shown in Supplementary Table 1(Table S1).

\subsection{S ribosomal DNA (16S rDNA) identification}

The contents of the cecum were taken aseptically and were detected by Shenzhen Huada Genomics Technology Service Co., Ltd. using 16S rDNA sequencing technology.

\subsection{Cytokine detection by cytometric bead array (CBA) and Flow CytoMetry (FCM)}

A colonic segment was mixed with $0.9 \% \mathrm{NaCl}$ saline at a mass ratio of 1:10 and then automatically homogenized with a homogenizer. The homogenate was centrifuged to obtain a supernatant $(3,000 \times g$, $4{ }^{\circ} \mathrm{C}, 10 \mathrm{~min}$ ). The levels of interleukin (IL)-1 $\beta$, IL-17, IL-6, monocyte chemotactic protein-1 (MCP-1), TNF-a, and interferon- $\gamma$ (IFN- $\gamma$ ) were determined by CBA following the manufacturer's instructions using a FACS Canto II flow cytometer.

IECs were extracted from small intestine with digestive juice, and incubated with Alexa Fluor 488-CD324 and PE-Reg $\triangle$ Y flow antibody for 30 min. Intestinal epithelial cells were labeled with CD324 and antibacterial proteins were labeled with Regllly. Then they were detected by flow cytometry.

\subsection{Fluorescence in situ hybridization (FISH)}

$4 \mu \mathrm{m}$ sections were prepared from paraffin embedded colon tissue for FISH. According to the manufacturer's instructions, bacterial infiltration of the colonic mucosa was detected using the EUB338I FISH probe with FITC labeled Kit (Guangzhou Exon Biotechnology Co., Ltd., China).

\subsection{Western blot analysis}


Colonic tissue was homogenized and centrifuged $\left(4{ }^{\circ} \mathrm{C}, 2,500 \times \mathrm{g}\right.$, and $\left.5 \mathrm{~min}\right)$. Cytoplasmic and nuclear proteins were extracted from the collected precipitate using cytoplasmic and nuclear protein extraction kits, respectively. The protein concentration was calculated by measuring optical density at $562 \mathrm{~nm}$ with a microplate reader. Proteins $(20 \mu \mathrm{g})$ were separated by sodium dodecyl sulfate polyacrylamide gel electrophoresis and then transferred onto a polyvinylidene difluoride membrane. The membrane was soaked in 5\% skim milk at room temperature for $1 \mathrm{~h}$ to block non-specific binding sites and then incubated with a primary antibody (TLR4, TLR5, NOD2, MyD88, RIP2 or NF-KB p65), followed by incubation with an appropriate secondary antibody. Positive immunoreactions were directly imaged using a chemiluminescence image analysis system with a Super ECL Plus ultra-sensitive luminescent solution.

\subsection{Semi-quantitative reverse transcription and polymerase chain reaction}

Total RNA was extracted from the colon with the TRIzol reagent. The purity and concentration of RNA were determined using an ultra-micro ultraviolet spectrophotometer, and the concentration was adjusted to $500-700 \mathrm{ng} / \mu \mathrm{L}$. DNA was removed from the total RNA using DNase with incubation at $42{ }^{\circ} \mathrm{C}$ for 5 min. cDNA was synthesized from $1 \mu \mathrm{g}$ of total RNA in a total volume of $20 \mu \mathrm{L}$ at the following conditions: $37^{\circ} \mathrm{C}$ for $15 \mathrm{~min}$, followed by $85^{\circ} \mathrm{C}$ for $5 \mathrm{~s}$ with a first-strand CDNA synthesis kit. SYBR® Premix Ex Taq ${ }^{\mathrm{TM}}$ ( $T$ li RNase H Plus) was used for amplification of cDNA. Reactions were performed in triplicate. We analyzed the relative expression of the Nod2, Rip2, and NF-KB p65 genes by comparing transcript levels of the target genes with that of the internal reference Gapdh. The sequences of the primers were as follows: Nod2: 5'-ACCATGTAGAAGCCATGCTGGAG-3' (forward) and 5'-CTTCACCGCAGCGAGATCAA-3' (reverse); Rip2: 5'-GCCATTGTGAGCCAGATGA-3' (forward) and 5'-ATTTGAAGGCGGTGCTTTG-3' (reverse); RelA (encoding NF-KB p65): 5'-ATGTGCATCGGCAAGTGG-3' (forward) and 5'CAGAAGTTGAGTTTCGGGTAG-3' (reverse); Gapdh: 5'-ACCACAGTCCATGCCATCAC-3' (forward) and 5'TCCACCACCCTGTTGCTGTA-3' (reverse). The amplification conditions were as follows: $95{ }^{\circ} \mathrm{C}$ for $30 \mathrm{~s}, 40$ cycles at $95^{\circ} \mathrm{C}$ for $5 \mathrm{~s}$ and $60^{\circ} \mathrm{C}$ for $30 \mathrm{~s}$, followed by $95^{\circ} \mathrm{C}$ for $10 \mathrm{~s}$ and generation of a dissociation curve from $65^{\circ} \mathrm{C}$ to $95^{\circ} \mathrm{C}$ at an increment of $0.5^{\circ} \mathrm{C}$ per $5 \mathrm{~s}$.

\subsection{Immunohistochemistry analysis}

Antigens were retrieved from frozen sections with citrate buffer, and the sections were then fixed with acetone and washed with phosphate-buffered saline. After that, $\mathrm{H}_{2} \mathrm{O}_{2}(20 \mu \mathrm{L} / \mathrm{sample})$ was added to inhibit the endogenous enzyme, followed by a blocking solution. The sections were exposed to antiNOD2, anti-RIP2, or anti-NF-KB p65 at $4{ }^{\circ} \mathrm{C}$ overnight and then to the SignalStain ${ }^{\circledR}$ Boost IHC detection reagent at room temperature for $30 \mathrm{~min}$. Images were visualized and captured using an Olympus microscope after staining with hematoxylin, dehydration, and sealing.

\subsection{Statistical analysis}

Data are expressed as the mean \pm standard deviation (SD). Differences between two groups were analyzed by the Student's $t$-test, and those among several groups were analyzed by one-way analysis of 
variance using SPSS (version 17.0). A $P$-value of $<0.05$ was considered statistically significant.

\section{Results}

\subsection{HPLC analysis of HQD}

It has been reported that HQD was confirmed to contain the indicator components paeoniflorin, glycyrrhizic acid, baicalin, wogonoside, and liquiritin, among which baicalin had the highest concentration, followed by wogonoside and glycyrrhizic acid ${ }^{[18]}$. And our results showed that the sample similarity of the 10 batches of HQD was more than 0.980 , based on the HQD fingerprints (Fig. 2), and the similarity analysis (Table 1 ) indicated that the quality of HQD was relatively stable.

Table 1

Similarity of ten batches of Huangqin decoction

\begin{tabular}{|ll|}
\hline Sample & Similarity \\
\hline Hungaqin Decoction S1 & 0.999 \\
\hline Hungaqin Decoction S2 & 0.999 \\
\hline Hungaqin Decoction S3 & 0.999 \\
\hline Hungaqin Decoction S4 & 0.998 \\
\hline Hungaqin Decoction S5 & 0.999 \\
\hline Hungaqin Decoction S6 & 0.998 \\
\hline Hungaqin Decoction S7 & 1.000 \\
\hline Hungaqin Decoction S8 & 1.000 \\
\hline Hungaqin Decoction S9 & 1.000 \\
\hline Hungaqin Decoction S10 & 0.998 \\
\hline
\end{tabular}

\subsection{Effects of HQD on colitis mice}

The experiments showed that the body weight of the mice significantly decreased in the model group compared with that of the control group, sulfasalazine group, middle-dose $(500 \mathrm{mg} / \mathrm{kg})$ and highdose $(1000 \mathrm{mg} / \mathrm{kg})$ HQD group. Notably, the body weight of the high-dose HQD group was closed to that of the control mice at the end of administration (Fig. 3a). The DAI score in the middle-dose and high-dose HQD groups significantly decreased $(P<0.01)$, consistent with the changes in the body weight (Fig. $3 \mathrm{C}$ ). While assessing the length of the colon, HQD also showed certain effects on the recovery of colonic length, especially at the high dose $(0.25 \mathrm{~g} / \mathrm{kg}, 0.5 \mathrm{~g} / \mathrm{kg}, 1 \mathrm{~g} / \mathrm{kg}$, Fig. 3b). 
Based on the results of HE staining of tissue sections (Fig. 3d), it was found that the colon in the model group showed obvious inflammatory cell infiltration and formed multiple ulcers. Meanwhile, HQD provided a therapeutic effect in a dose-dependent manner. Comparing with those in the control group, the counts of white blood cells, monocytes, and granulocytes significantly increased in the model group; however, the counts of red blood cells (RBC) and the levels of hemoglobin (HGB) showed opposite trends $(P<0.01)$. HQD and sulfasalazine improved the symptoms observed in the model group $(P<0.01$ or $P<$ 0.05; Fig. 3e).

\subsection{Effects of HQD on intestinal flora}

Compared with the control group, OTU in DSS group decreased significantly, and which were recovered after intervention with HQD (1000 mg/kg, Fig. 4a). What's more, the results of cluster analysis showed that HQD improved the imbalance of intestinal flora in mice with colitis and tended to the normal level (Fig. 4b and Fig. 4c). According to the results of a diversity analysis, observed species index, chao index, ace index and shannon index of intestinal flora decreased $(P \otimes 0.05)$, while simpson index increased significantly after DSS administration. Observed species index, chao index and ace index were all recovered after treatment with HQD, and there was significant difference compared with the model group (Fig. 4d).

In addition, the phylum classification of intestinal flora species showed that Bacteroidetes decreased, while Deferribacteres and Firmicutes increased significantly in colitis mice (Fig. 4e). The class classification showed that Actinobacteria, Bacteroidetes and Epsilonproteobacteria decreased, while Bacilli, Betaproteobacteria, Clostridia, Deferribacteres increased significantly in colitis mice (Fig. 4e). Sulfasalazine and HQD obviously recovered the Deferribacteres at the phylum and class level. The family classification showed that Helicobacteraceae, S24-7 decreased, Alcaligenaceae, Anaplasmataceae, Bifidobacteriaceae, Deferribacteraceae, Lachnospiraceae and Ruminococcaceae increased significantly in colitis mice (Fig. 4e). Sulfasalazine and HQD obviously recovered the Alcaligenaceae and Deferribacteraceae at the family level.

\subsection{Effects of HQD on intestinal barrier and PRRs}

As shown in Fig. 5a, the colonic mucosal bacterial infiltration was more severe in the $3 \%$ DSS group than the control group and was reduced after the administration of HQD $(1000 \mathrm{mg} / \mathrm{kg})$ or Sulfasalazine. Compared with the control group, the expression of Regllly in IECs of mice in the $3 \%$ DSS group increased significantly, which were ameliorated with HQD or Sulfasalazine (Fig. 5b). What's more, HQD inhibited the increase of TLR4 and NOD2 protein in colon of mice with colitis, especially NOD2 (Fig. 5c \& Fig. 5d). But the expression of TLR5 protein in HQD group was not significantly changed compared with the model group. And also, western blot analysis showed that HQD $(1000 \mathrm{mg} / \mathrm{kg})$ had no significant effect on the downstream pathway protein MyD88 of TLR4 or TLR5, but it inhibited the activation of protein RIP2 in the downstream pathway of NOD2 (Fig. 6a).

\subsection{Effects of HQD on NOD2-dependent pathway}


NOD2, RIP2, and NF-KB p65 are the key proteins in the NOD2 inflammatory signaling pathway. It was demonstrated by semi-quantitative polymerase chain reaction, and immunohistochemistry $(\mathrm{IHC})$ that the colons from the control mice had low levels of NOD2, RIP2, and NF-KB p65 expression, while the mice from the model group with DSS-induced colitis mainly showed overexpression of NOD2, RIP2, and NF-KB p65 in inflamed colon tissues ( $P<0.01$; Fig. 6b \& Fig. 6c). In the sulfasalazine and HQD-treated groups, expression of NOD2, RIP2, and NF-KB p65 decreased, especially in the middle - and high-dose HQD groups $(P<0.01$ or $P<0.05)$.

\subsection{Effects of HQD on inflammatory cytokines}

The levels of inflammatory cytokines, including IL-1ß (Fig. 7a), IL-17(Fig. 7b), MCP-1(Fig. 7c), TNFa(Fig. 7d), IFN-y(Fig. 7e), and IL-6(Fig. 7f), were significantly higher in colon tissue of the mice from the model group than in that of the control group $(P<0.01)$, and TNF-a was found at the highest level. The above markers were restored, to varying degrees, in the groups treated with different doses of HQD and with sulfasalazine, among which the medium- and high-dose HQD groups showed statistically significant differences compared with the model group $(P<0.01$ or $P<0.05)$.

\section{Discussion}

In this study, the results of the similarity evaluation and principal component analysis of different batches of HQD showed that the chemical composition of HQD was basically same, which were consistent with what has been previously reported. Meanwhile, it was demonstrated that the quality of HQD was relatively stable, which provides a basis for the study of its pharmacodynamics and pharmacological mechanism.

After administration of DSS, the mice exhibited unfavorable symptoms such as weight loss, dull hair and poor food intake owing to diarrhea and hematochezia. The morphology of the colon showed redness and swelling, and the length of the colon became shorter, which were due to the excessive hypertrophy of the muscular layer of the colon in colitis mice. In addition, H\&E results showed increased infiltration of inflammatory cells in the submucosa of the colon, which was caused by the activation of inflammatory chemokines and the recruitment of immune cells to the lesion sites. However, these pathological symptoms were improved after treated with sulfasalazine (SASP, commonly used in clinical treatment of IBD) and HQD. Furthermore, SASP and HQD reduced the DAI score and repaired mucosal ulcers of the colon in colitis mice. An increase in the number of WBC and changes in their classification indicated that inflammation appeared in mice with $3 \% \mathrm{DSS}$. And the loss of blood, caused by hematochezia in the mice, resulted in decreasing numbers of RBC and $\mathrm{HGB}$. HQD reduced the number of WBC and restored the number of RBC and the content of HGB in colitis mice, especially the middle-dose $(500 \mathrm{mg} / \mathrm{kg}$ ) and the high-dose $(1000 \mathrm{mg} / \mathrm{kg})$ of HQD. Taken together, the data confirmed the positive effect of HQD on colitis mice.

Based on the efficacy of HQD on the treatment of DSS-induced colitis mice, we further explored its specific mechanism of action. Previous studies have shown that the intestinal flora of colitis mice is 
dysfunctional, and its components or metabolites activate the PRRs of intestinal epithelial cells and release inflammatory factors, resulting in the destruction of intestinal barrier and further aggravating intestinal inflammation ${ }^{[19]}$. $16 S$ rDNA results showed that HQD increased the OUT number of intestinal flora and the species richness of microflora of colitis mice, which were consistent with previous study ${ }^{[20]}$. And cluster analysis results also implied HQD regulated the intestinal flora and restored the diversity of intestinal flora in mice with colitis. Moreover, the data of relative abundance analysis of intestinal flora at phylum, class and family level showed that HQD regulated intestinal flora of colitis mice, especially on Deferribacteres, Deferribacteraceae and Alcaligenaceae. Studies have confirmed that the imbalance of intestinal flora led to conditional pathogenic bacteria invading intestinal mucosa. Reglll $\gamma$, an important bacteriostatic factor in the innate immune system, expressed in large quantities after intestinal injury, and played a role in enhancing the innate immune defense in the early stage of inflammation. The expression of Reglll y protein raised with the increase of bacterial infiltration and inflammation. Thus, Reglll $y$ is used as an important indicator of tissue injury, especially bacterial infiltration. In this study, the intestinal contents and bacteria of colitis mice directly contacted the intestinal epithelial cells due to the destruction of epithelial barrier caused by DSS, which stimulated the up-regulation of Reglll y expression. The results of FISH and flow analysis showed that the colonic bacterial infiltration and the expression of Reglll $y$ in intestinal epithelial cells of colitis mice decreased after treatment with SASP and HQD, which indirectly reflected the protective effect of HQD on intestinal barrier.

In addition, PAMPs in the intestinal cavity of colitis mice promoted the activation of PRRs in intestinal epithelial cells and increased their expression. LPS (a component of the outer wall of gram-negative bacteria), flagellin (a granular protein that makes up the flagellar fibers of bacteria) and MDP (a smallest structural unit with immune adjuvant activity in the cytoskeleton of Mycobacterium) are ligands of TLR4, TLR5 and NOD2, respectively. It has been confirmed that the activation of PRRs (TLR4, TLR5 and NOD2) led to the aggravation of inflammation in colitis mice. Our data also showed that the expression of TLR4, TLR5 and NOD2 proteins increased in the colon of mice with DSS-induced colitis, which were decreased significantly after the intervention of HQD. The study further detected the changes of TLR4/TLR5 shared downstream pathway protein MyD88 and NOD2 downstream pathway protein RIP2. And the results showed that HQD (1000 mg/kg) significantly inhibited the expression of RIP2 protein, but had little effect on the expression of MyD88 protein, which was consistent with previous study ${ }^{[21]}$. Thus, we further studied the NOD2/NF- $\mathrm{KB}$ signaling pathway.

As demonstrated by our data, imbalance of intestinal flora lead to the binding of PAMPs in the intestinal cavity to the PRRs of intestinal epithelial cells, which further activates the PRRs-mediated pathway and exacerbates inflammation. MDP, existing in the intestinal cavity, recognized NOD2 in IECs or immunocytes and then activated the downstream signaling molecule RIP2. And RIP2 interacted with the tumor necrosis receptor family and transcription factors activated by the NF-KB pathway and mitogenactivated protein kinase (MAPK) pathway ${ }^{[22]}$. NF-KB was transferred from the cytoplasm to the nucleus and binded to the promoter region of target genes, which resulted in the transcription of genes encoding proinflammatory mediators and led to a cascade of inflammatory reactions and recruitment of 
macrophages to the site with inflammation ${ }^{[23]}$. Hence, activation of the NF-KB signaling pathway is a key contributor to the damage or even failure of the body tissue. NF-kB, existing in the form of a heterodimer, consists of two subunits, p50 and p65 [24]. The p65 subunit is a main proinflammatory subunit, whose activation plays a key role in the pathogenesis of IBD. And many IBD-associated proinflammatory cytokines have NF-KB-binding sites in their promoter regions ${ }^{[25,26]}$. Furthermore, HQD inhibited the mRNA expression of NOD2, Rip2, and NF-KB p65, especially in the high-dose HQD group (1000 mg/kg). As shown in the results of IHC, the group treated with HQD $(1000 \mathrm{mg} / \mathrm{kg})$ showed an even better suppression of NOD2, Rip2, and NF-KB p65 than that treated with sulfasalazine. Moreover, the increase of intestinal pro-inflammatory cytokines in IBD mice further destroyed the intestinal barrier and aggravated the inflammatory response. The expression of cytokines (including IL-1, IL-17, MCP-1, TNF-a, IFN- - , IL-6, etc.) were obviously increased in the supernatant of a colonic homogenate and induced proinflammatory effects, which play an important role in the pathogenesis of IBD ${ }^{[27,28]}$. However, the pathological symptoms were improved after treated with sulfasalazine and HQD. And there was no difference between the high-dose HQD group (1000 mg/kg) and sulfasalazine group.

\section{Conclusion}

This study showed that HQD $(1000 \mathrm{mg} / \mathrm{kg})$ has a positive effect on the imbalance of intestinal flora in colitis mice, which may be characterized as the inhibition of NOD2-dependent pathway (Figure. 8).

\section{Abbreviations}

HQD, Huangqin Decoction; PAMPs, Pathogen-associated molecular pattern; PRRs, pattern recognition receptor; TLR4, Toll Like Receptor 4; TLR5, Toll Like Receptor 5; MDP, Muramyl Dipeptide; UC, ulcerative colitis; DSS, Dextran sulfate sodium; IBD, inflammatory bowel disease; IL-1 $\beta$, Interleukin-1 $\beta$; MCP-1, monocyte chemotactic protein-1; TNF-a, Tumor necrosis factor-a; IFN-y, Interferon- - ; IL-6, Interleukin-6; IL17, Interleukin-17; WBC, White blood cell; RBC, Red blood cell; HGB, Hemoglobin; Mon, Monocytes; Gran, Granulocyte.

\section{Declarations}

\section{Acknowledgements}

Not applicable

\section{Funding}

This study was supported by the National Natural Science Foundation of China (grant number No. 81673668 and 81703785); Natural Science Foundation of Guangdong Province (grant number 
2018A030313447); and the Young Talents Project of Guangzhou University of Chinese Medicine (grant number qnyc20190104).

\section{Conflict of interests}

The authors declare that there are no conflicts of interest associated with this publication.

\section{Author contributions}

Huang, S., Luo, X., Zhou, L.: contributed to the conception and design of the study

He, J., Chen, Y., Wang, X., Li, Y., Su, Y., Li, X.: contributed to the material and technological support.

Huang, S., He, J., Yang, G., Luo, S.: contributed to the acquisition of data or analysis and interpretation of data

Huang, S., Luo, X.: contributed to the writing of articles.

\section{Availability of data and materials}

The data and materials used or analyzed during the current study are available from the corresponding author on reasonable request.

\section{Consent for publication}

All the authors consent to publish this work in traditional Chinese medicine.

\section{Ethics approval and consent to participate}

Not applicable.

\section{References}

1. UNGARO R, MEHANDRU S, ALLEN P B, et al. Ulcerative colitis [J]. Lancet, 2017, 389(10080): 1756-70.

2. NISHIDA A, INOUE R, INATOMI O, et al. Gut microbiota in the pathogenesis of inflammatory bowel disease [J]. Clin J Gastroenterol, 2018, 11(1): 1-10.

3. WEINGARDEN A R, VAUGHN B P. Intestinal microbiota, fecal microbiota transplantation, and inflammatory bowel disease [J]. Gut Microbes, 2017, 8(3): 238-52. 
4. Zhang $X$, Zhang $S$, He R, et al. Intestinal microbial barrier function and pathogenic virulence[J]. Progress in Modern Biomedicine. 2017, 17(31): 6186-90.

5. Zhang Y, Shen N. Characteristics of intestinal flora in patients with ulcerative colitis[J]. Hebei Medical Journal. 2018, 40(07): 1054-7.

6. WANG C, LI Q, REN J. Microbiota-Immune Interaction in the Pathogenesis of Gut-Derived Infection [J]. Front Immunol, 2019, 10(1873.

7. GEREMIA A, BIANCHERI P, ALLAN P, et al. Innate and adaptive immunity in inflammatory bowel disease [J]. Autoimmun Rev, 2014, 13(1): 3-10.

8. GERMAIN A, GUEANT R M, CHAMAILLARD $M$, et al. NOD2 gene variant is a risk factor for postoperative complications in patients with Crohn's disease: A genetic association study [J]. Surgery, 2016, 160(1): 74-80.

9. LUO S, DENG X, LIU Q, et al. Emodin ameliorates ulcerative colitis by the flagellin-TLR5 dependent pathway in mice [J]. Int Immunopharmacol, 2018, 59(269-75.

10. WANG J P, DONG L N, WANG M, et al. MiR-146a regulates the development of ulcerative colitis via mediating the TLR4/MyD88/NF-kappaB signaling pathway [J]. Eur Rev Med Pharmacol Sci, 2019, 23(5): 2151-7.

11. Xi J. Clinical Study of Huangqin Decoction in Treating Ulcerative Colitis[D]. Beijing University Of Chinese Medicine. 2006.

12. Ning $Y$, Xing $Y$, Tian M, et al. Research Progress of Huangqin Decoction[J]. Chinese Journal of Information on Traditional Chinese Medicine. 2014, 04): 188-90.

13. ZOU Y, LIN J, LI W, et al. Huangqin-tang ameliorates dextran sodium sulphate-induced colitis by regulating intestinal epithelial cell homeostasis, inflammation and immune response [J]. Sci Rep, 2016, 6(39299.

14. Wang $D$, Wang $Y$, Wang $Y$, et al. Study on the Regulatory Effect of Huangqin Decoction on TLR4/MyD88 Pathway in Ulcerative Colitis Rats[J]. Acta Pharmaceutica Sinica. 2016, 51(10): 155863.

15. Wang L. Research Progress of Jingfang Huangqin Decoction[J]. Chinese Medicine Modern Distance Education of China. 2020;18(04):191-194.

16. YANG Y, CHEN G, YANG Q, et al. Gut microbiota drives the attenuation of dextran sulphate sodiuminduced colitis by Huangqin decoction [J]. Oncotarget, 2017, 8(30): 48863-74.

17. COOPER H S, MURTHY S N, SHAH R S, et al. Clinicopathologic study of dextran sulfate sodium experimental murine colitis [J]. Lab Invest, 1993, 69(2): 238-49.

18. HUANG S, FU Y, XU B, et al. Wogonoside alleviates colitis by improving intestinal epithelial barrier function via the MLCK/pMLC2 pathway [J]. Phytomedicine, 2020, 68(153179.

19. SINA C, KEMPER C, DERER S. The intestinal complement system in inflammatory bowel disease: Shaping intestinal barrier function [J]. Semin Immunol, 2018, 37(66-73. 
20. LI M Y, LUO H J, WU X, et al. Anti-Inflammatory Effects of Huangqin Decoction on Dextran Sulfate Sodium-Induced Ulcerative Colitis in Mice Through Regulation of the Gut Microbiota and Suppression of the Ras-PI3K-Akt-HIF-1alpha and NF-kappaB Pathways [J]. Front Pharmacol, 2019, 10(1552.

21. WANG D F, WANG Y L, WANG Y W, et al. [Effect of Huangqin Tang on the function of regulatory TLR4/MyD88 signal pathway in rats with ulcerative colitis] [J]. Yao Xue Xue Bao, 2016, 51(10): 155863.

22. ABBOTT D W, YANG Y, HUTTI J E, et al. Coordinated regulation of Toll-like receptor and NOD2 signaling by K63-linked polyubiquitin chains [J]. Molecular and cellular biology, 2007, 27(17): 601225.

23. WINDHEIM M, LANG C, PEGGIE M, et al. Molecular mechanisms involved in the regulation of cytokine production by muramyl dipeptide [J]. The Biochemical journal, 2007, 404(2): 179-90.

24. PANDAY A, INDA M E, BAGAM P, et al. Transcription Factor NF-kappaB: An Update on Intervention Strategies [J]. Archivum immunologiae et therapiae experimentalis, 2016, 64(6): 463-83.

25. QIAN J, ZHAO W, MIAO X, et al. Sam68 modulates apoptosis of intestinal epithelial cells via mediating NF-kappaB activation in ulcerative colitis [J]. Molecular immunology, 2016, 75(48-59.

26. SPERANSKII A I, KOSTYUK S V, KALASHNIKOVA E A, et al. [Enrichment of extracellular DNA from the cultivation medium of human peripheral blood mononuclears with genomic $\mathrm{CpG}$ rich fragments results in increased cell production of IL- 6 and TNF-a via activation of the NF-kB signaling pathway] [J]. Biomeditsinskaia khimiia, 2016, 62(3): 331-40.

27. LIU Q L, HUANG L, ZHAO Q J, et al. Relationship between serum interleukin-17 level and inflammatory bowel disease [J]. Journal of biological regulators and homeostatic agents, 2016, 30(1): 181-8.

28. LIN A N, LI Y Q, ZHONG M X, et al. [Expressions of inflammatory cytokines in intestinal mucosa and their prognostic value in patients with ulcerative colitis] [J]. Nan fang yi ke da xue xue bao = Journal of Southern Medical University, 2016, 36(12): 1712-7.

\section{Figures}




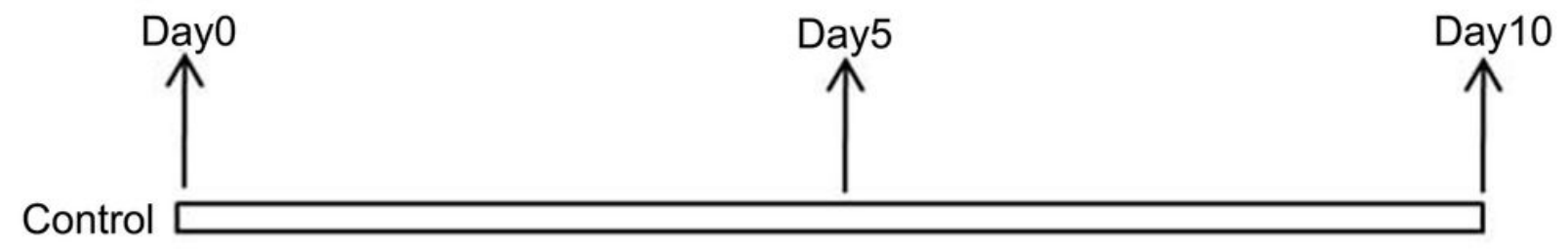

DSS

Sulfasalazine

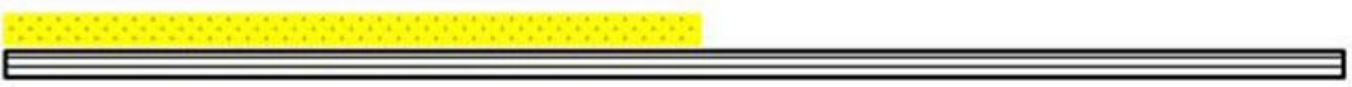

$\mathrm{HQD}(250 \mathrm{mg} / \mathrm{kg}$ )

HQD $(500 \mathrm{mg} / \mathrm{kg})$ -

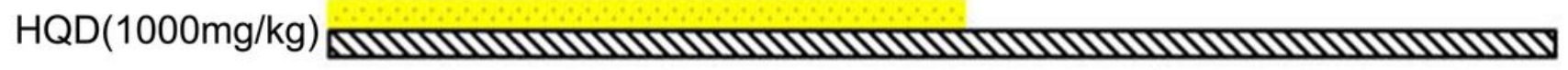

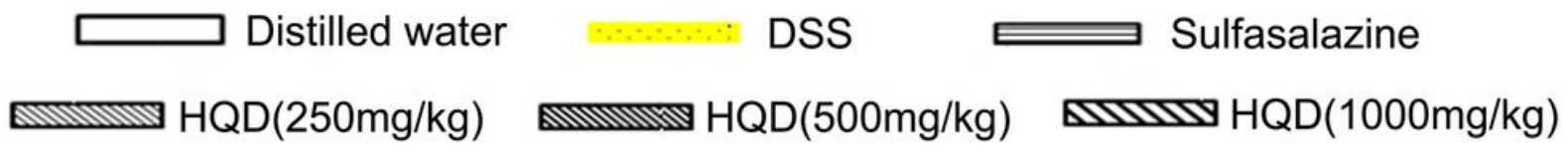

\section{Figure 1}

Treatment of HQD on colitis mice induced by DSS. The mice in the control group had free access to sterile water, while those in the other groups drank 3\% DSS freely for 5 days and then drank sterile water. Meanwhile, the mice in the control and model groups were administered with sterile water, while the other four groups were given the drugs. The drugs were administered for a total of 10 days, and the experiment was carried out on day 11 . 


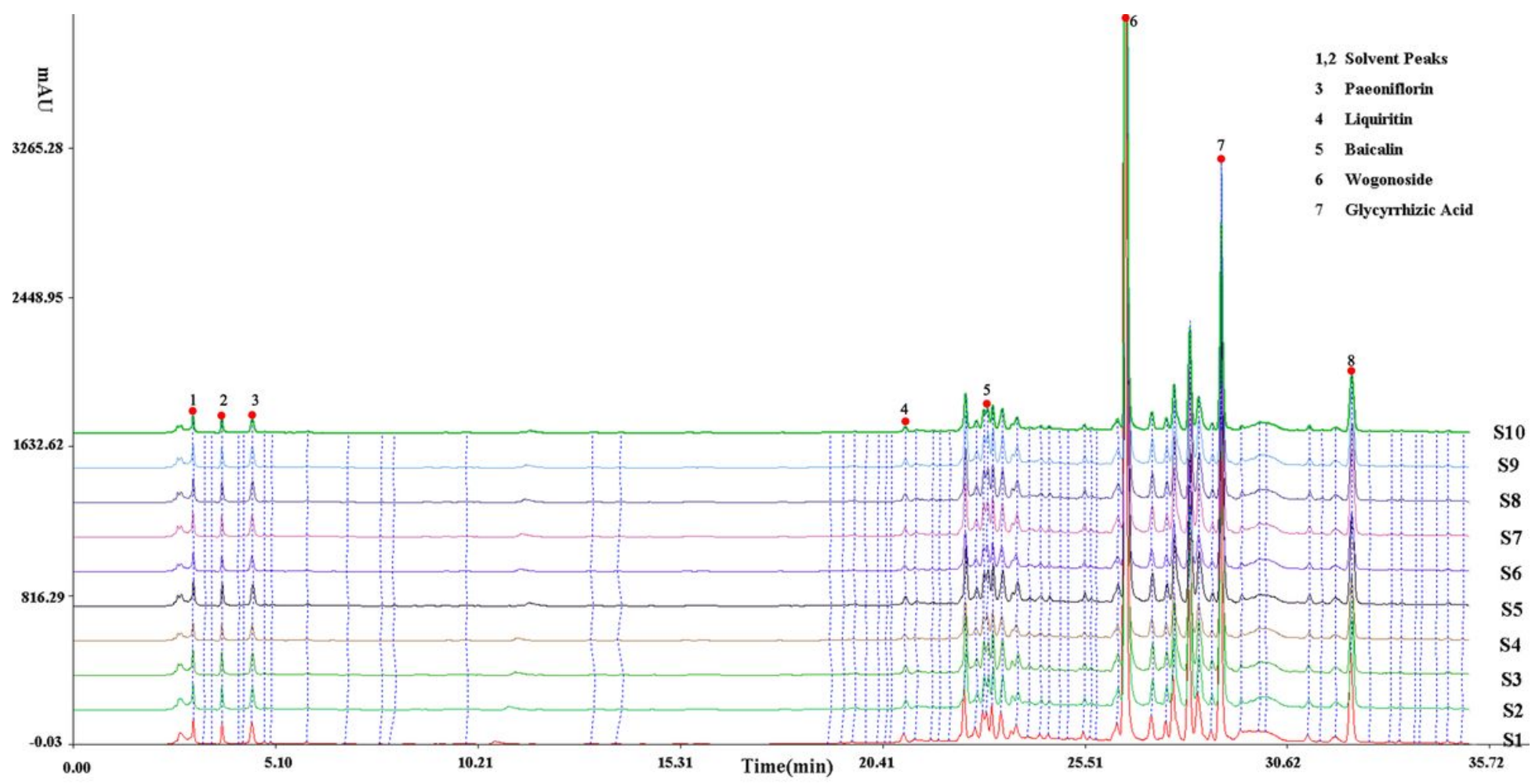

Figure 2

Composition of HQD. Fingerprints of HQD from 10 batches. The sample similarity of the HQD batches was more than 0.980 , which proved that the quality of HQD was stable. 1,2. Solvent Peaks; 3. Paeoniflorin; 4. Liquiritin; 5. Baicalin; 6. Wogonoside; 7, Glycyrrhizic Acid. 
a.

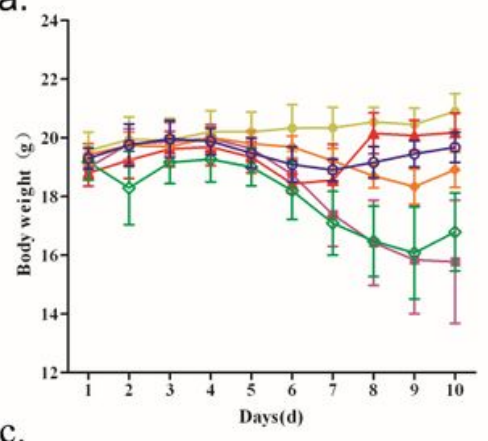

c.

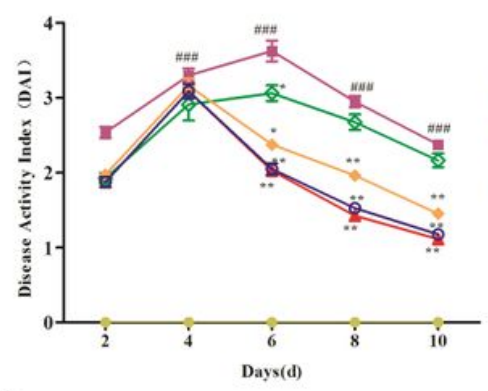

e.

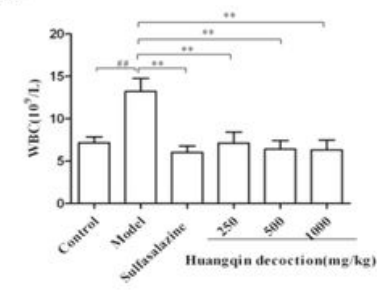

b.
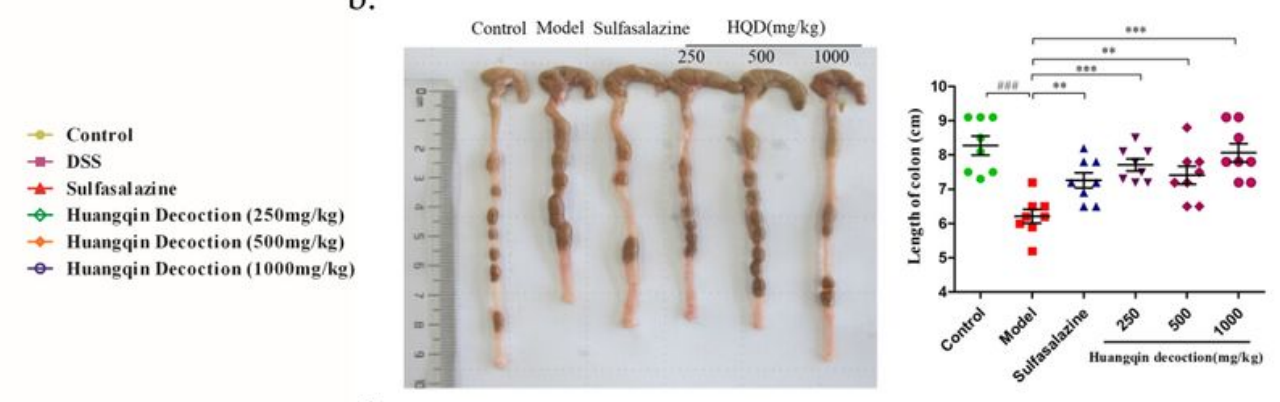

d.
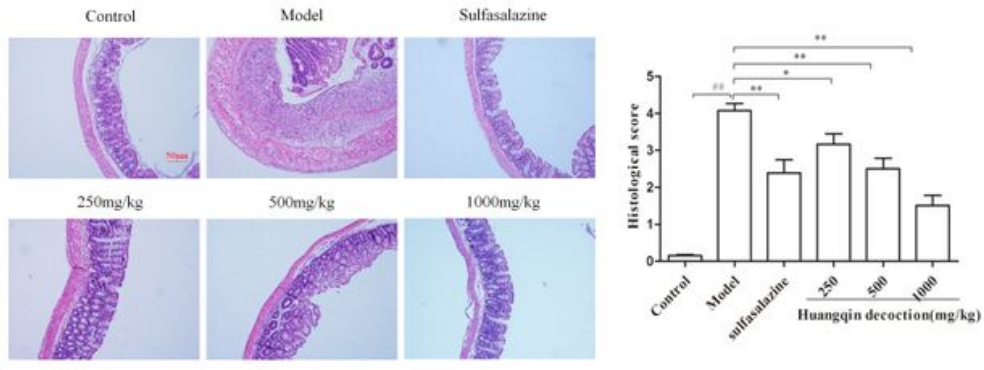

Figure 3

Effect of HQD on colitis mice. (a) Effects of HQD on the body weight of colitis mice. (b) Effects of HQD on the length of the colon in DSS-induced colitis mice ( $n=8$ per group). (c) Effects of HQD on the DAI score of DSS-induced colitis mice ( $\mathrm{n}=8$ per group). (d) Effects of HQD on the colon in DSS-induced colitis mice. Scale bar: $50 \mu \mathrm{m}$ (e) Effects of HQD on blood cells in DSS-induced colitis mice $(n=10$ per group). HQD and sulfasalazine improved the symptoms in the model group. ${ }^{*} P<0.01,{ }^{*} \mathrm{P}<0.001 \mathrm{vs}$. DSS-treated group; \#P $<0.05, \# \# P<0.01$ model vs. control. 
a.

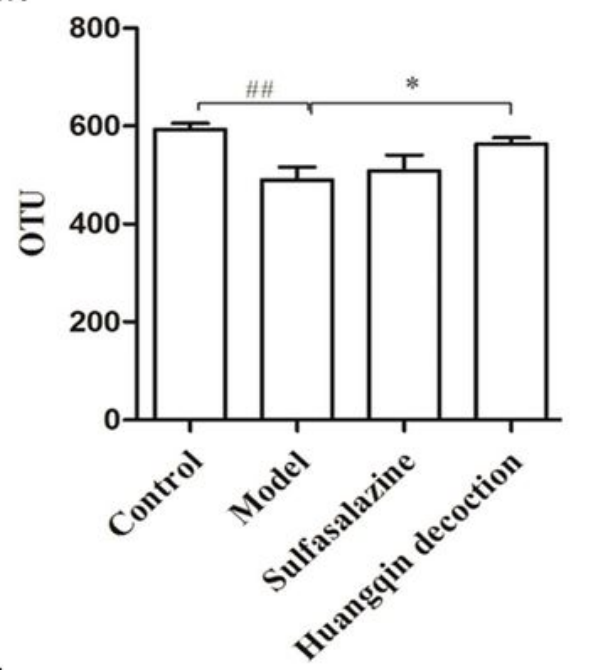

b.

d.

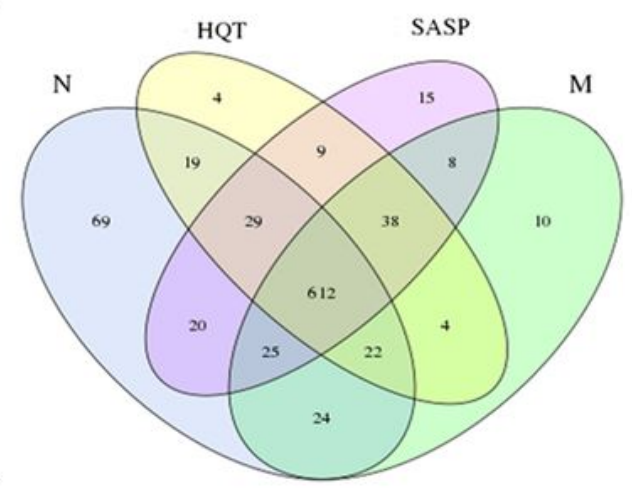

c.

weighted_unifrac cluster tree

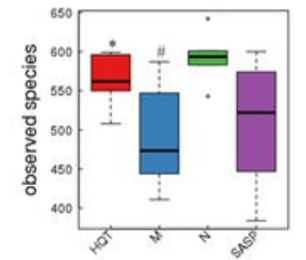

e.

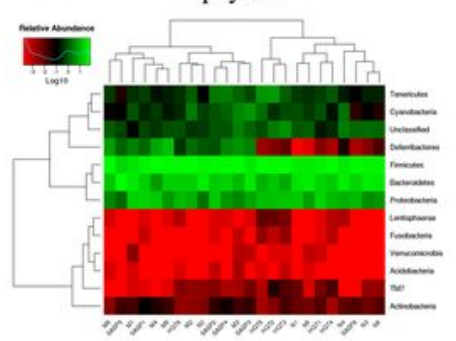

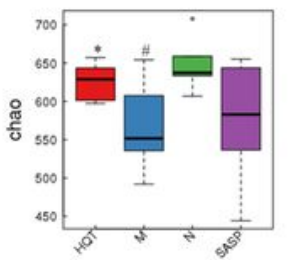

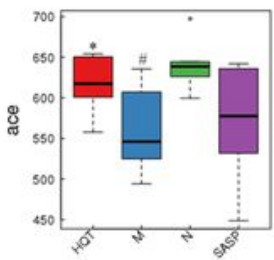

class

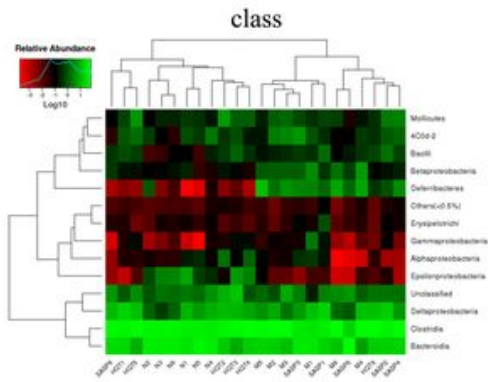

- HQT

- $\mathrm{M}$

- $\mathrm{N}$

- SASP

\section{Figure 4}

Effect of HQD on intestinal flora of colitis mice. (a) Impacts of HQD on the OUTs of intestinal microflora. ( $b$ and c) The cluster analysis of intestinal microflora in colitis mice. (d) The alpha diversity of intestinal microflora in colitis mice. (e) The histogram of intestinal microflora species classification in phylum, class and family in colitis mice. N, Control; M, Model; HQT, Huangqin decoction; SASP, sulfasalazine. $\# \mathrm{P}<0.05$, \#\#P<0.01 control vs. DSS-treated group, ${ }^{\star} \mathrm{P}<0.05$ vs. DSS-treated group. 
a.
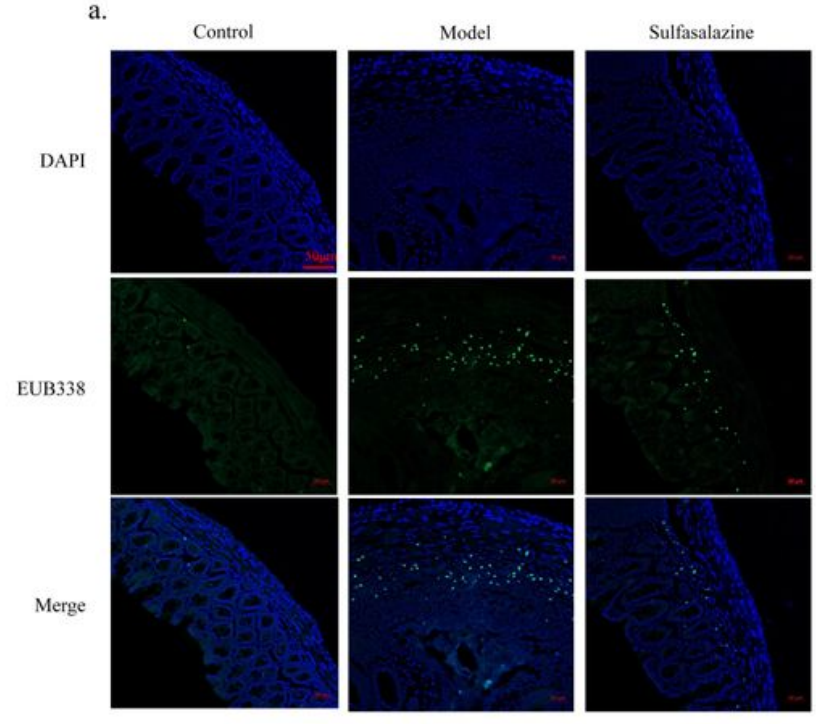

b.

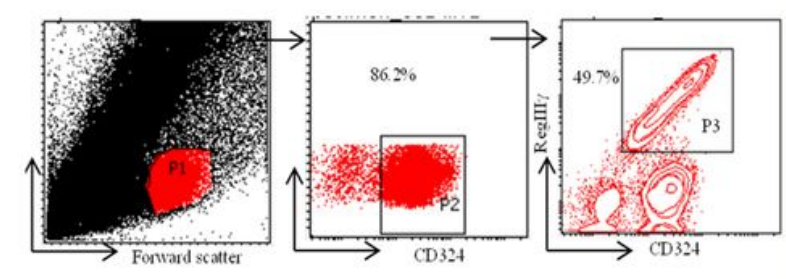

Huangqin decoction
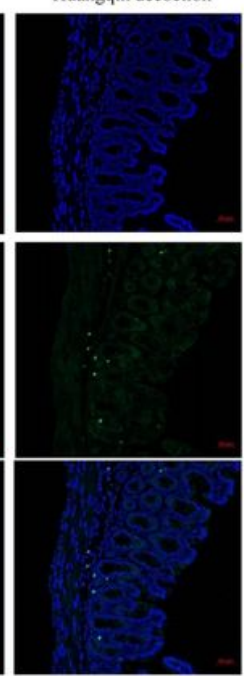

c.
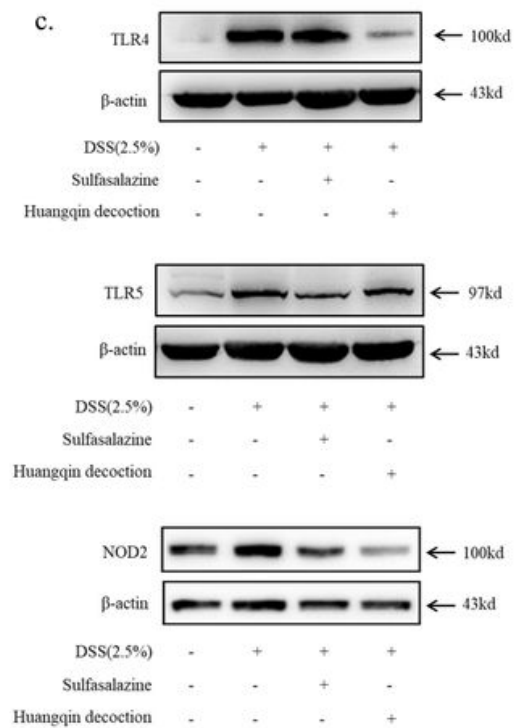

d.
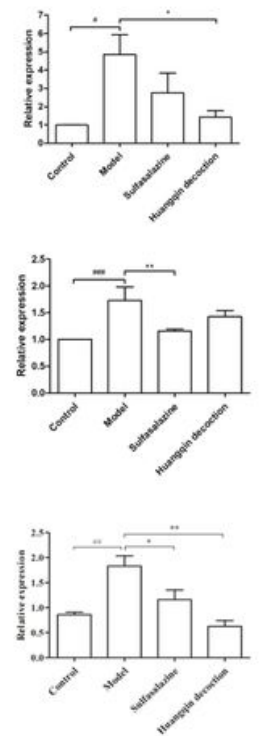

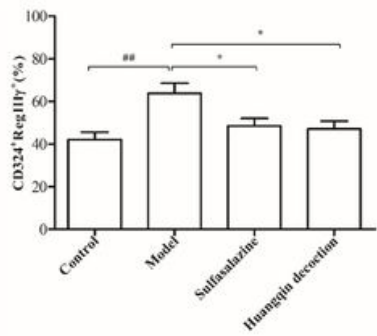

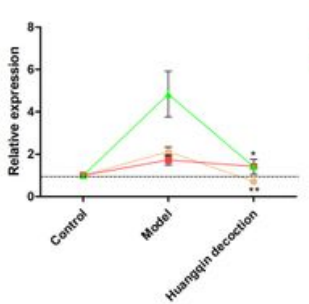

\section{Figure 5}

Effect of HQD on PRRs and intestinal barrier function of colitis mice. (a) Impacts of HQD on the bacterial submucosal invasion in colitis mice by FISH. Bacteria labeled with green fluorescence, the cell nucleus

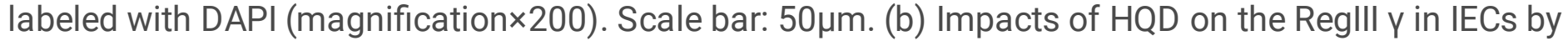
FCM. The analytical protocol of IECs expressed Reglll $y$ and the statistical results of CD324+Regllly+ IECs mice. (c) Impacts of HQD on PRRs (TLR4, TLR5, NOD2) in colitis mice by western blot. Quantification of protein expression was performed by densitometric analysis of western blots. Expression was normalized to that of $\beta$-actin. Data are expressed as the means $\mathbb{S D}$ of three independent experiments. (d) Comparison of HQD on the expression of three PRRs (TLR4, TLR5, NOD2) proteins. \#P<0.05, \#\#P<0.01, $\# \# \# \mathrm{P}<0.001$ control vs. model, ${ }^{\star} \mathrm{P}<0.05, \star * \mathrm{P}<0.01$ vs. model. 
a.
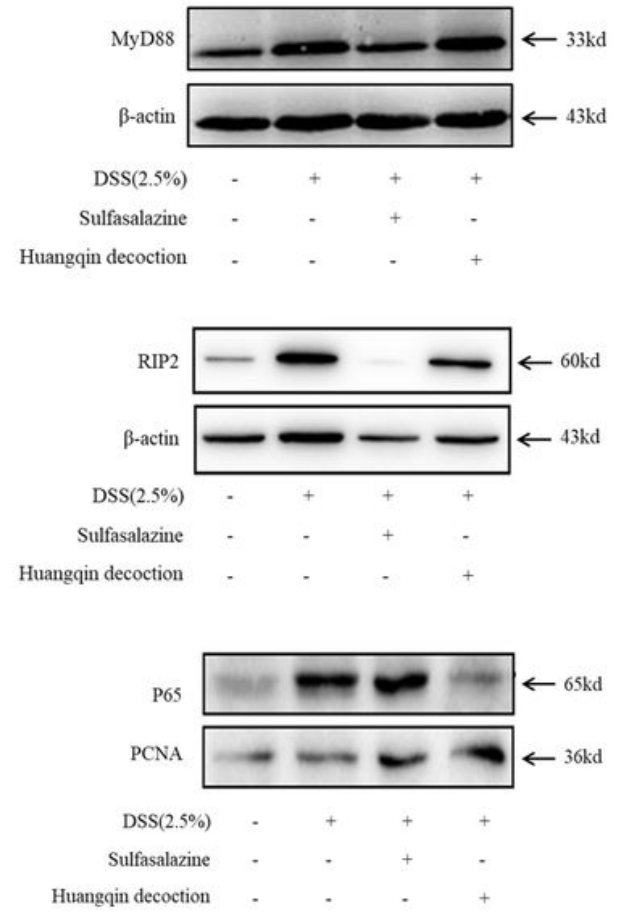

b.

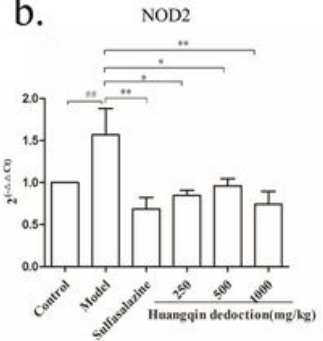

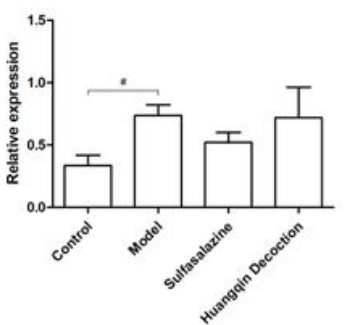
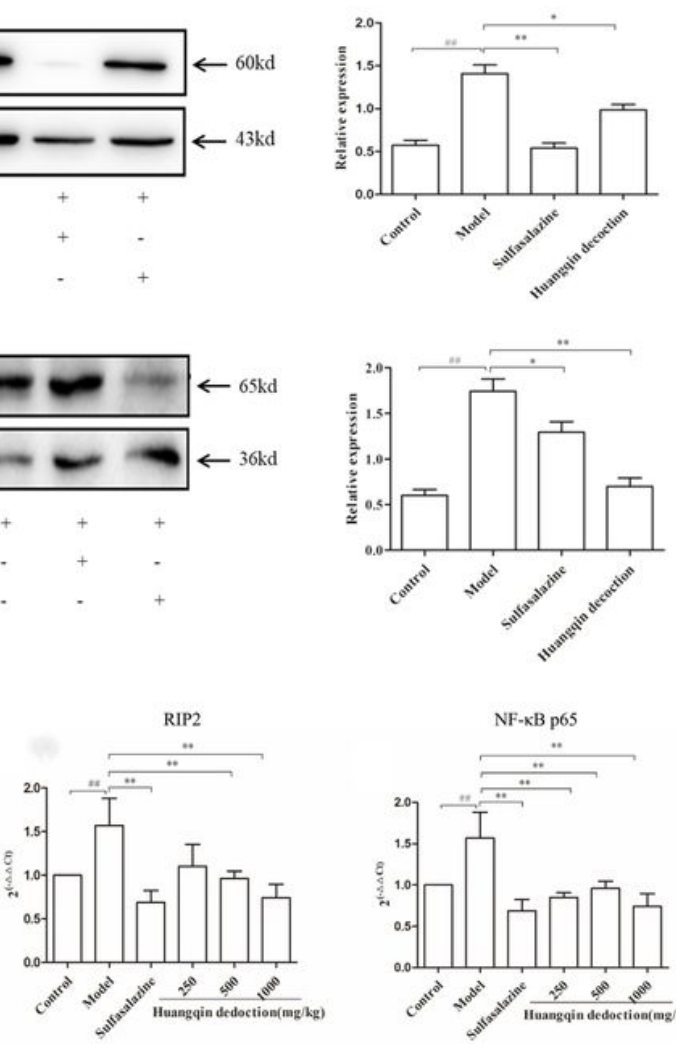

c.
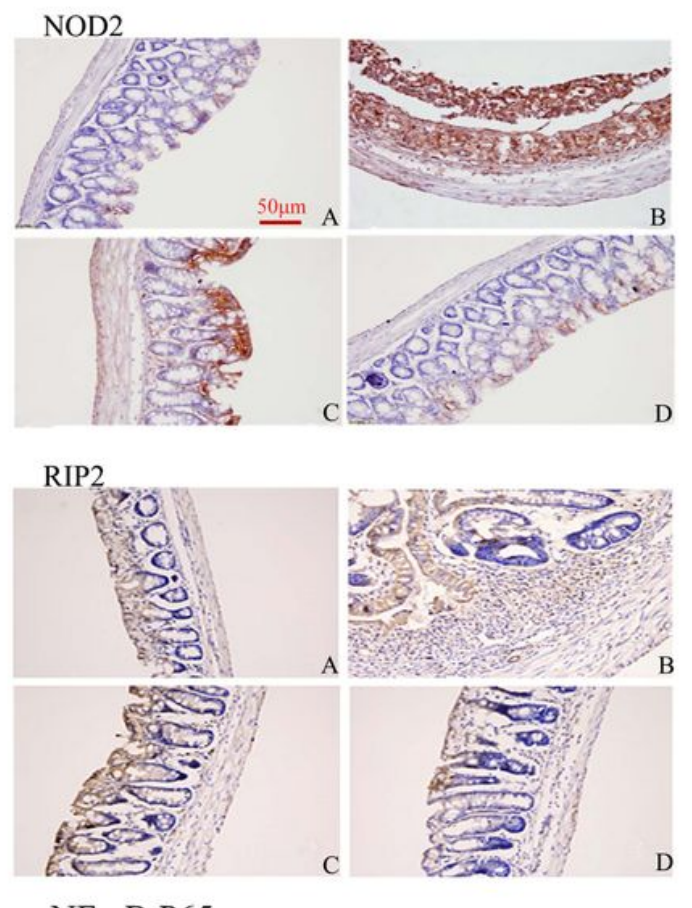

NF-kB P65

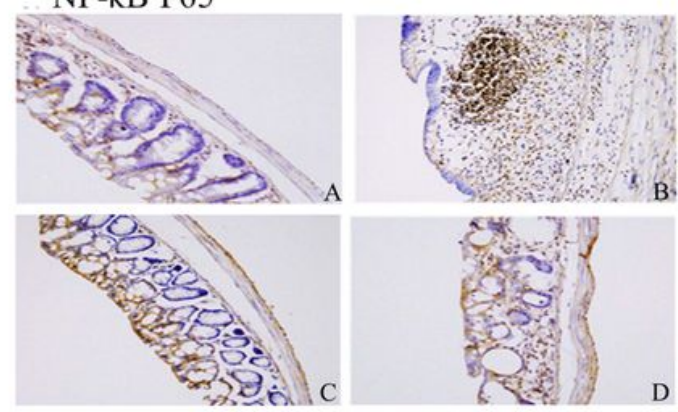

\section{Figure 6}

Effects of HQD on NOD2-dependent pathway. (a) Impacts of HQD on the proteins of MyD88, RIP2 and P65 in colitis mice by western blot. Expression was normalized to that of $\beta$-actin and proliferating cell

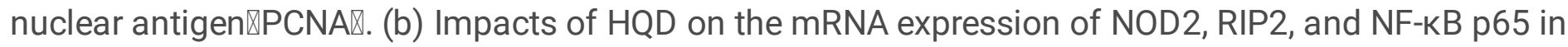
colon samples isolated from mice ( $\mathrm{n}=6$ per group). Expression was normalized to that of Gapdh. (c) Impacts of HQD on the expression of proteins in the NOD2 signaling pathway in DSS-induced colitis in mice, as determined by IHC (A, Control; B, model; C, sulfasalazine; D, HQD. Magnification $\times 200)$. Scale bar: $50 \mu \mathrm{m}$. Data are expressed as the means $\otimes S D$ of three independent experiments. ${ }^{*} P<0.01,{ }^{\star} P<<0.001$ vs. DSS-treated group; \#P $<0.05, \# \# P<0.01$ model vs. control. 
a.

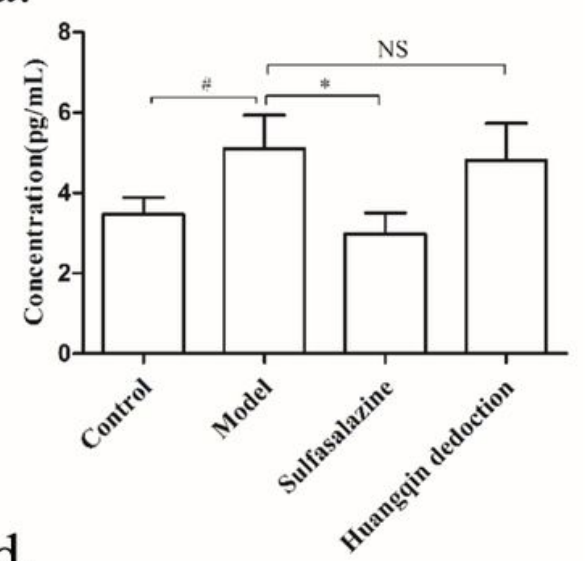

d.

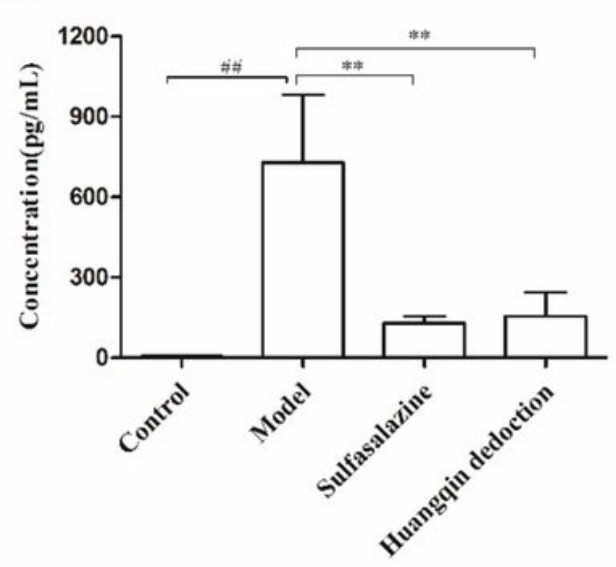

b.

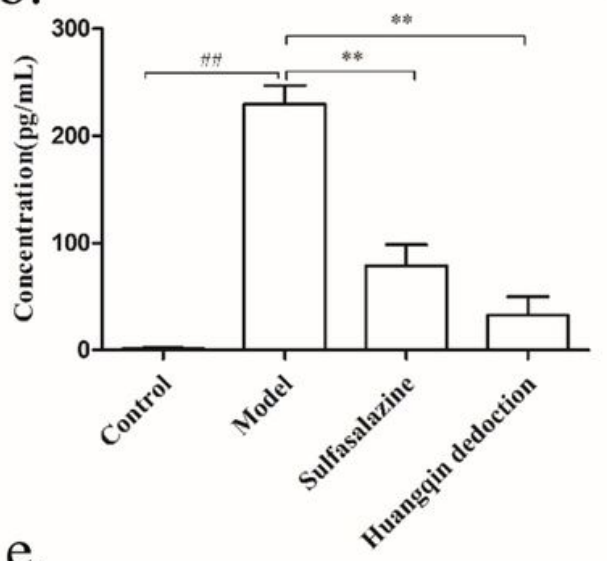

e.

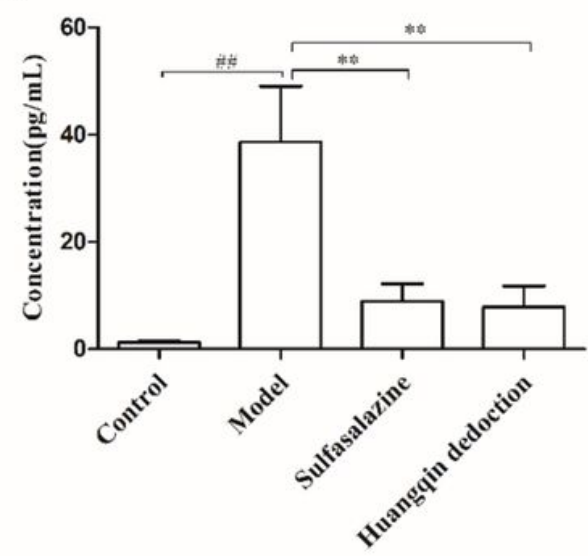

C.

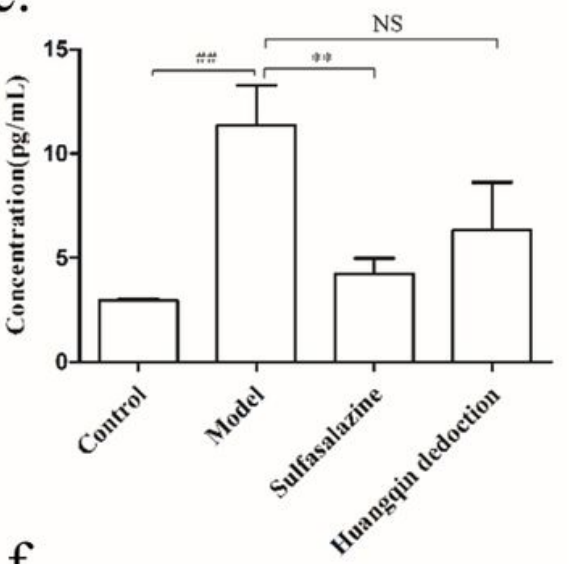

f.

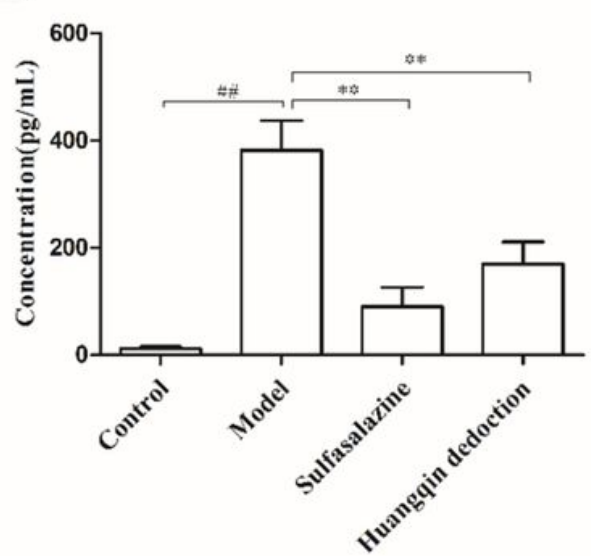

Figure 7

Effects of HQD on cytokines in the colon of DSS-induced colitis mice. Sulfasalazine and HQD, especially the medium and high HQD doses, inhibited the release of inflammatory mediators ( $\mathrm{n}=8$ per group): (a) IL-13; (b) IL-17; (c) MCP-1; (d) TNF-a; (e) IFN- $y$; (f) IL-6. \#P < 0.05, \#\#P < 0.01 model vs. control; *P < 0.05, $\star \star P<0.01$ model vs. HQD-treated group. 


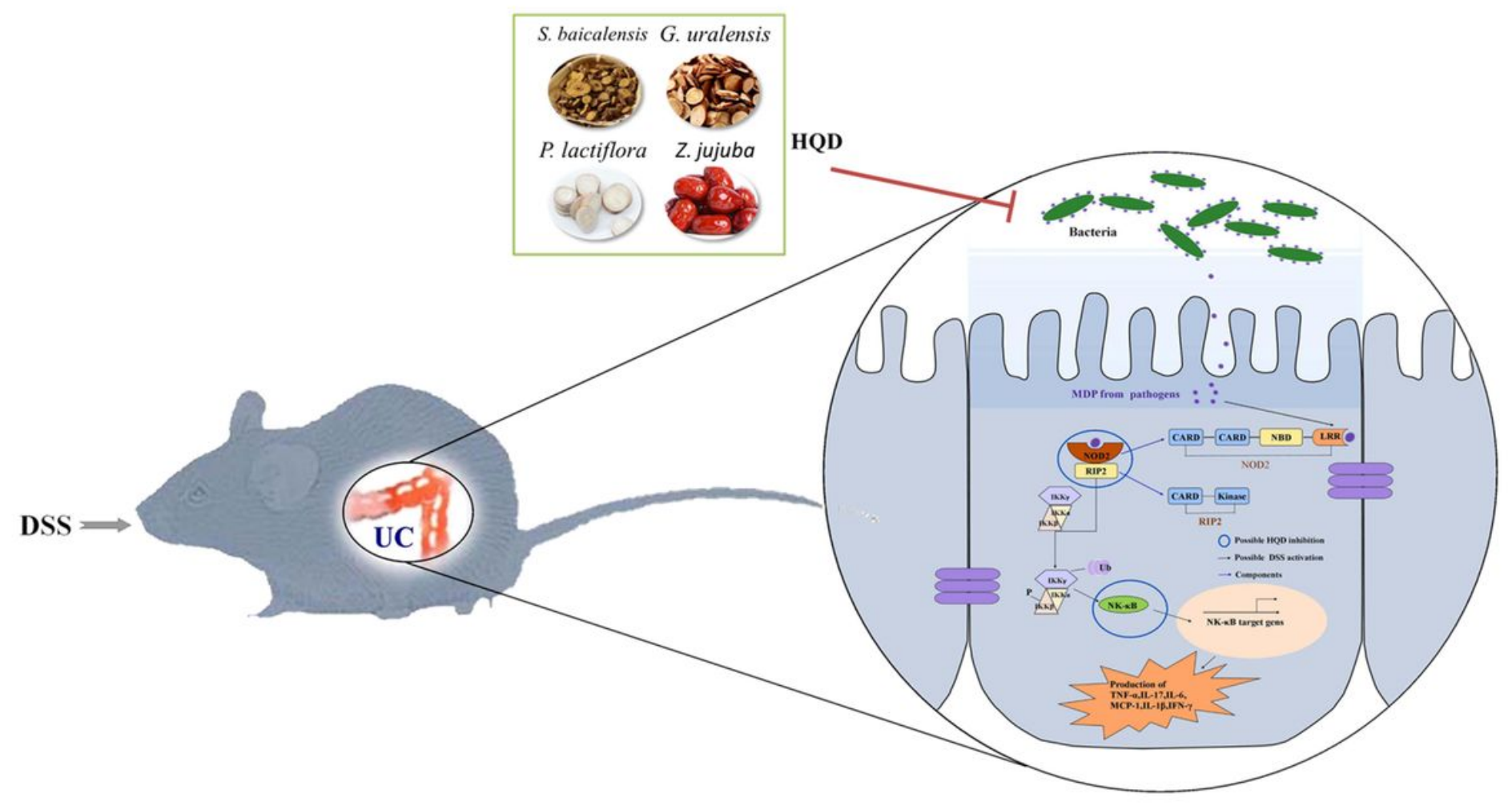

Figure 8

The mechanism of $\mathrm{HQD}(1 \mathrm{~g} / \mathrm{kg})$ in regulating the intestinal flora of colitis mice, which may be closely characterized as the inhibition of the activation of NOD2 - dependent pathway.

\section{Supplementary Files}

This is a list of supplementary files associated with this preprint. Click to download.

- Supplementary.docx 